\title{
Histological assessment of the quality of groundmeat semi-finished products
}

\author{
Elena Chugunova, \\ FSBEI HE Perm SATU, Perm, the Russian Federation, chugunova.elen@yandex.ru
}

\begin{abstract}
The article deals with the problem of quality of pork and beef groundmeat semi-finished products of A category. The research was conducted in the city of Perm in 2021. The study used organoleptic and histological research methods. The organoleptic analysis showed full compliance of the tested products with the requirements of regulatory documents. As a result of histological research, violations of GOST 329512014 requirements were recorded: in a number of samples, the mass fraction of skeletal muscles was in the ratio of 1:1 with adipose tissue. Most of the samples $(85 \%)$ included the presence of connective and cartilaginous tissues. The biological hazard of the tested samples of meat products was established $-100 \%$ contamination by parasites of the genus Sarcocystis spp was noted. The number of sarcocysts in the samples studied by us varied from 3 units in the preparation to 4 units in the field of view.
\end{abstract}

\section{Introduction}

Many scientific papers [1-4] are devoted to the issue of assessing the quality of food products, including meat culinary products, semi-finished products. Nevertheless, this issue remains relevant and practically significant. The problem of quality and safety of meat products is multifaceted, and various violations can occur, starting with production and ending with storage on the counter of a retail chain.

Over the past decade, the range of groundmeat products has increased manyfold, while at the same time, the number of cattle in the meat production direction has significantly decreased. According to the reports of the Ministry of Agriculture of the Russian Federation and Rosstat data, only in 2020 beef production decreased by $7.4 \%$, poultry meat - by $6.4 \%$, while the volume of industrial production of semi-finished products (meat, meat-containing, chilled, frozen) increased by $9.7 \%$ over the same period. To be fair, it should be noted that in 2020, pork production increased by $1 \%$ [5]. It is no secret that the meat industry is undergoing significant changes. The production of semi-finished meat products is one of the rapidly developing industries [6]. Technologists create new recipes for meat products, including fish meat, by-products, animal fats, vegetable components, including dietary fiber, etc. [7-11]. Thus, the task of the meat industry is to increase the scale of production in order to provide the population with food by reducing the use of

\footnotetext{
* Corresponding author: chugunova.elen@yandex.ru
} 
animal protein and including various additives of plant origin in the recipe. According to Article 10 of the Law of the Russian Federation "On consumer protection", manufacturers must indicate information about the ingredients on the label [12]. Nevertheless, the labeling does not always reflect the actual ingredients of the product.

Another aspect of the problem of the quality of meat products is compliance with the rules for storing meat products. It is known that during freezing, especially during repeated freezing and thawing, there is a defrosting of muscle fibers, which negatively affects the consumer and physico-chemical properties of the product [13].

Based on the above, the theoretical and practical significance of our research is undeniable. The purpose of the work is to perform a histological assessment of a number of groundmeat products purchased in the retail network of the city of Perm.

Research tasks:

1. to perform sampling and sample fixation;

2. to evaluate the organoleptic properties of the samples;

3. to determine product ingredients and quality of muscle fibers by histological method.

\section{Materials and methods}

The research material was chilled minced meat breaded semi-finished products of A category $(n=20)$, purchased in the retail network of the city of Perm. Taking into account the requirements of Federal Law No. 294 [14], all test samples were encrypted and numbered from 1 to 20: No. 1-10 - beef products; 11-20 - pork products.

Organoleptic evaluation of the samples was carried out in an office with uniform, shadowless lighting according to GOST 9959-2015 [15]. The appearance, view on the cut, color, smell and taste (after heat treatment) of semi-finished products were evaluated.

The histological method of research was carried out according to GOST 19496-2013 [16], the test material was previously cleaned from breading. The sample pieces taken for the study $(1.5 \times 1.5 \mathrm{~cm}$ in size $)$ were placed in plastic cassettes for cutting with dimensions of $2.8 \times 4.0 \times 0.5 \mathrm{~cm}$. The tissue areas in the cassette were filled with $10 \%$ neutral buffered formalin ( $\mathrm{pH}$ 7.0-7.2). Next, the material was posted with alcohols of increasing strength for dehydration and compaction of the tissue using a LEICA TP 1020 automatic histoprocessor (Leica Biosystems Nussloch $\mathrm{GmbH}$, Germany) with a specified posting cycle of 18 hours.

After posting, the pieces were poured into a particularly pure paraffin ("histomix" medium) with a melting point of $56^{\circ} \mathrm{C}$. For this purpose, the device Thermo scientific Histostar (Thermo Fisher Scientific, USA) was used. From the obtained paraffin blocks, sections with a thickness of 2-3 microns were made on a microtome semi-automatic Microm HM 325(MICROM International GmbH, Germany).

Microscopy of histological preparations was performed on an optical microscope MT 5300 (Meiji Techno, Japan).

\section{Results and discussion}

Organoleptic evaluation of the samples showed their full compliance with the requirements of GOST 32951-2014 [17]. Externally, the samples represented meat products evenly covered with breadcrumbs, and minced meat of a uniform consistency was visualized on the section. Beef meat products were red in color, pork semi-finished products were pinkred in color. No foreign odors were detected, the products had a taste characteristic of beef and pork, respectively. 
Histological analysis showed the presence of skeletal muscle, cartilage, connective and adipose tissue in the samples of meat semi-finished products.

Skeletal muscles located in fragments prevailed in two samples of pork semi-finished products and in one beef product (Fig. 1). The figure clearly visualizes the transverse and longitudinal sections of myofibrils and basophilic colored nuclei displaced to the periphery of the muscle fiber.

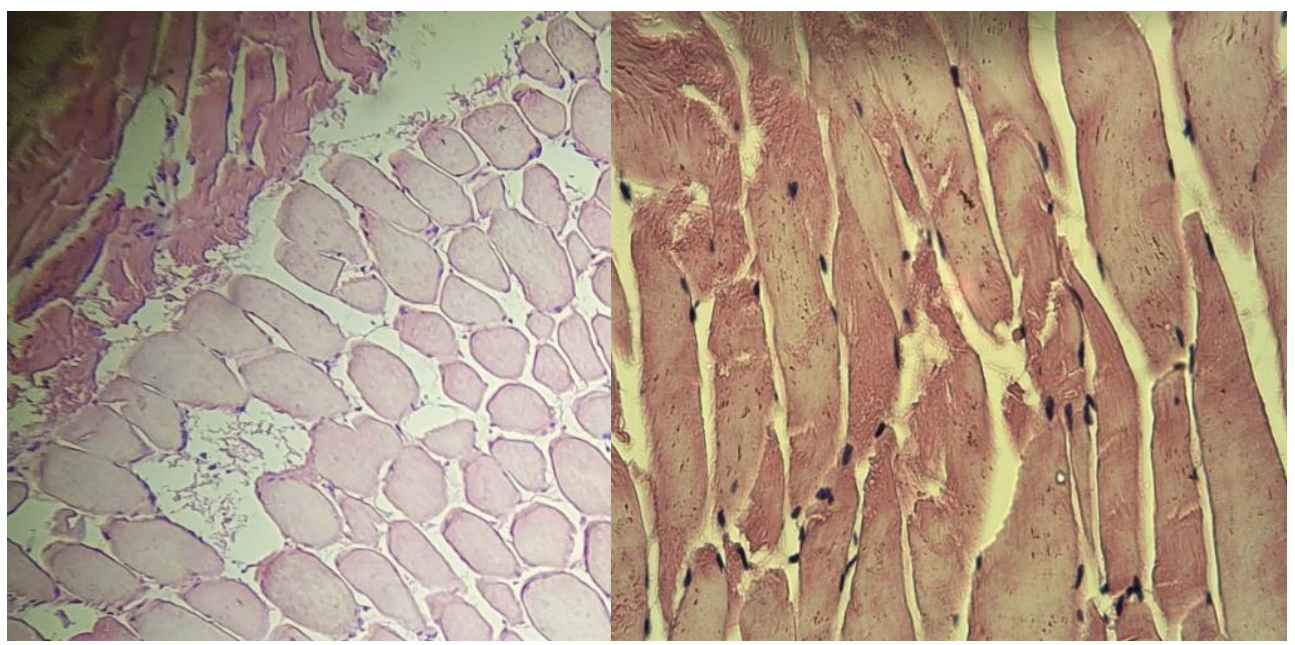

Pork. Ob.x10 Oc.x10

Beef. Ob.x40 Oc.x10

Fig. 1. Skeletal muscles in minced meat products. Color with hematoxylin eosin.

Histological analysis of a number of samples revealed defrosted muscle cells (Fig. 2).

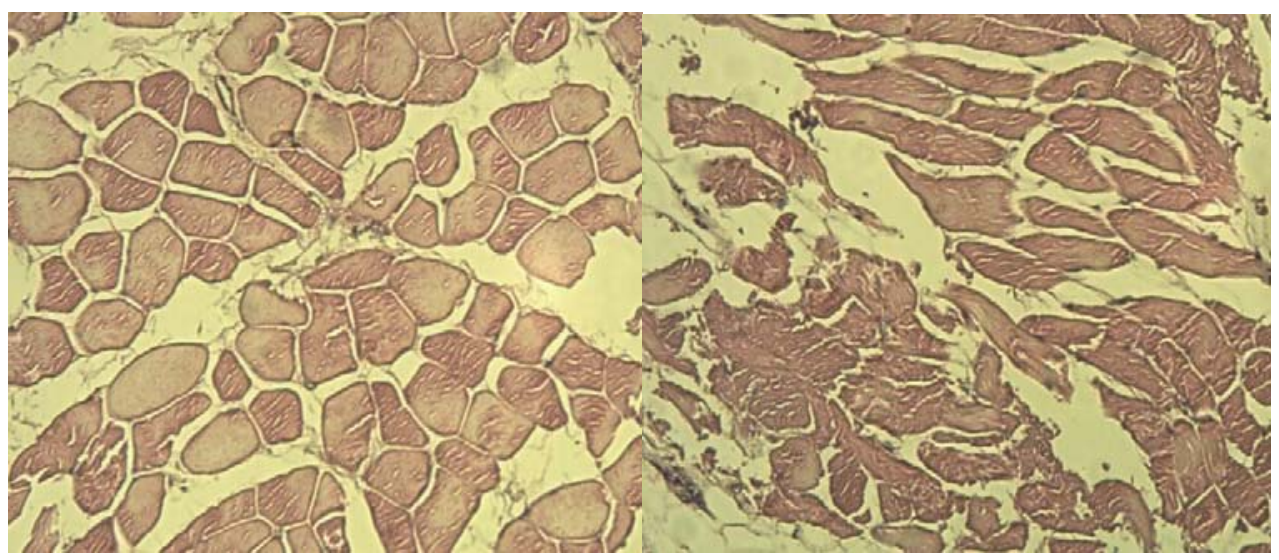

Fig. 2. Defrosted muscle fibers. Ob.x10 Oc.x10 Color with hematoxylin eosin.

According to the results obtained, it was concluded that the chilled semi-finished products are made from frozen raw materials and the deformation of myofibrils occurred due to the ice formation in the muscle thickness. Moreover, the raw materials were frozen, judging by the changes we noted, in the traditional way in the freezer, although at present there is a technical possibility to perform ultra-fast freezing. Scientists have proved that the use of shock freezing of natural portioned meat semi-finished products causes small mechanical destruction of muscle fibers and preserves the high moisture-binding and moisture-retaining abilities of muscle tissue $[18,19]$. 
In some fields of vision, cells with unevenly colored cytoplasm, devoid of nuclei, and alternation of pale zones and hypereosinophilic areas was found (Fig. 3).

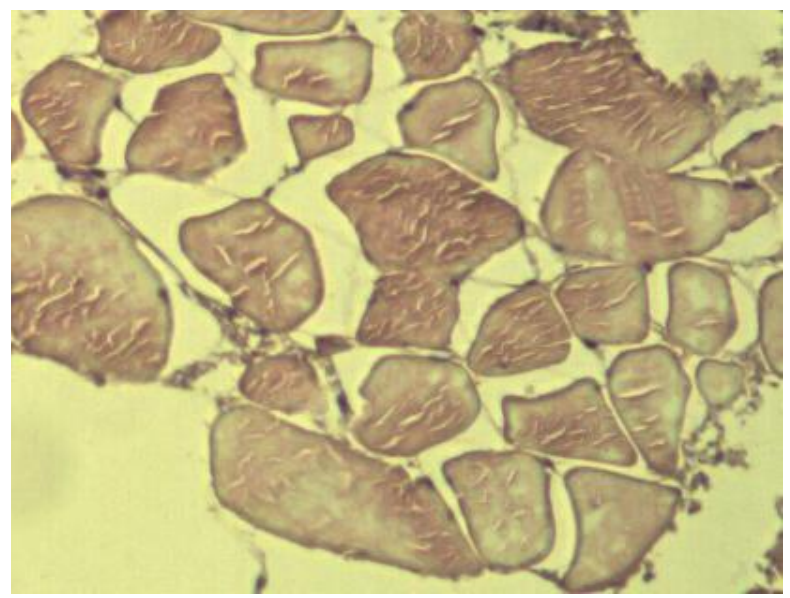

Fig. 3. Deformed muscle cells. Ob.x10 Oc.x10 Color with hematoxylin eosin.

All samples of the tested semi-finished products contained fat in their composition, and in some semi-finished products the amount of fat was about half of the product weight (Fig. 4).

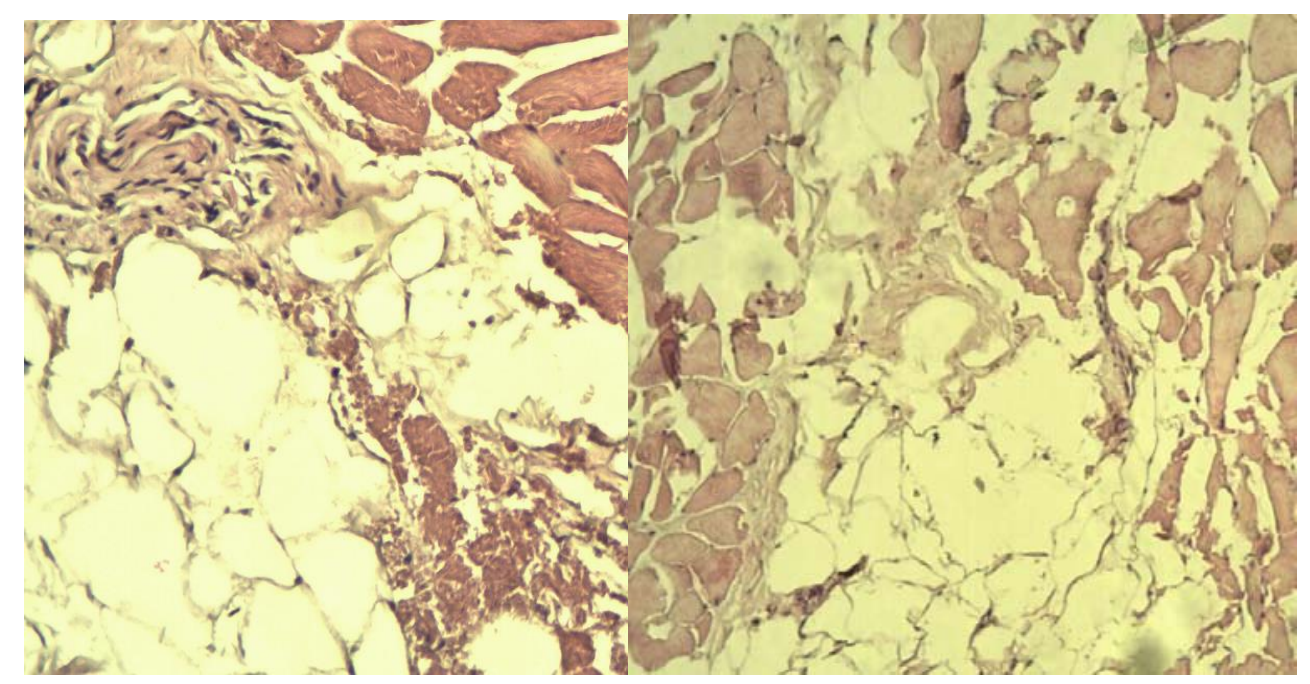

Fig. 4. Fat cells and myofibrils. Ob.x10 Oc.x10 Color with hematoxylin eosin.

Most of the test samples of groundmeat products contained connective tissue. At the same time, the ratio of connective tissue to muscle fibers varied from about 10 to $20 \%$. In some samples, along with the connective tissue, the presence of cartilage tissue was found (Fig. 5). 


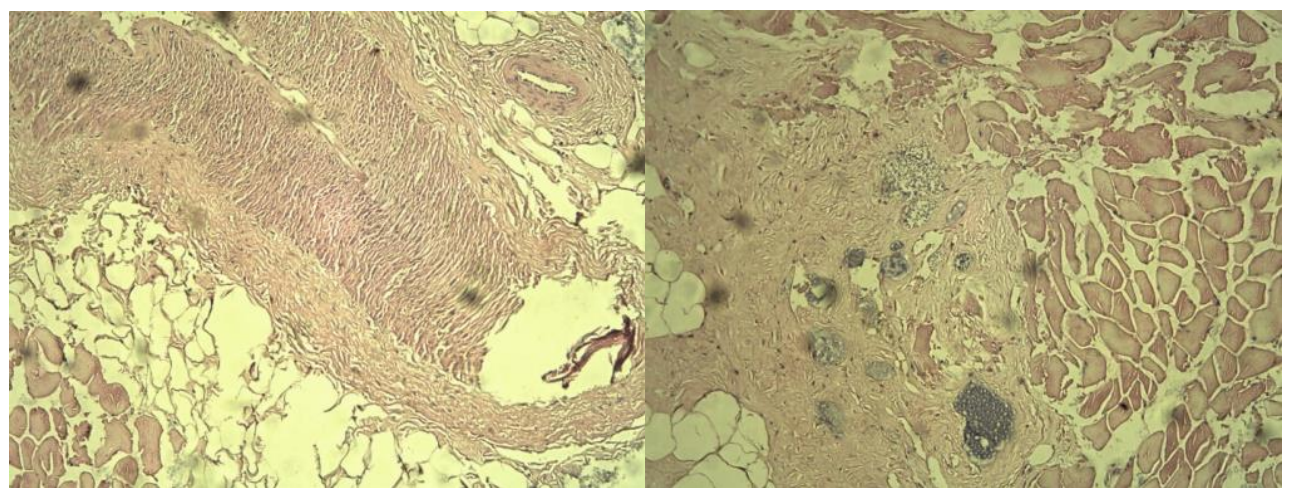

Fig. 5. Connective, cartilage and muscle tissue in groundmeat products. Ob.x10 Oc.x10 Color with hematoxylin eosin.

Thus, 17 out of 20 test samples according to the results of histological analysis can be attributed to falsifications, since the composition contains non-meat ingredients not provided for by the recipe. This high-quality falsification is certainly a violation of the requirements of regulatory documentation for meat semi-finished products and it reduces their cost and nutritional value, but does not pose a biological danger to humans, unlike the presence of parasites in meat. In this regard, we want to focus on the following fact: in all the test samples of semi-finished products, sarcocysts were in the cytoplasm of individual myocytes (Fig. 6).

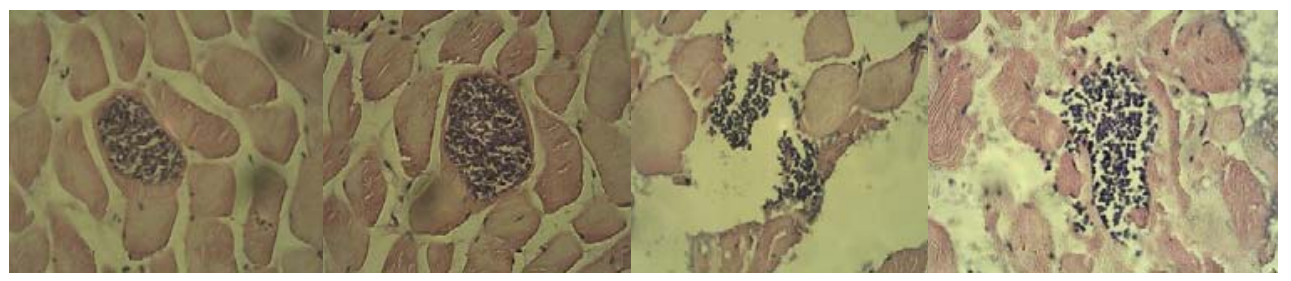

Fig. 6. Parasites of the genus Sarcocystis spp. in myocytes. Ob.x40 Oc.x10. Color with hematoxylin eosin.

The number of sarcocysts in the samples studied by us varied from 3 units in the preparation to 4 units in the field of view (with ob.x40 oc.x10). Moreover, as follows from Figure 6, during the technological meat processing (grinding, homogenization), the sarcocyst shell can retain its integrity or break. In the latter case, trophozoites and toxins come out of the sarcocyst, which can cause allergic reactions. Also, when eating an insufficiently heat-treated meat product, sarcocysts colonize the villi of the small intestine mucosa and lead to the development of human intestinal sarcocystosis [20, 21, 22].

\section{Conclusions}

According to the research results, it can be concluded that histological analysis is a reliable way to determine the composition of groundmeat products and semi-finished products, but, unfortunately, GOST 32951-2014 cl. 6.13 implies histological identification of semifinished products only when there are differences in the composition of the raw materials used [17]. The problem of falsification lies not only in the dishonesty of producers, but also in the imperfection of regulatory documents regulating the requirements for meat and meat products [23, 24, 25]. Of course, after the Russian Federation's accession to the WTO, many standards lost their relevance, or were revised and supplemented, or introduced for 
the first time [26 - 30]. TR TS 034/2013 establishes microbiological safety standards for slaughter products and meat products, requirements for physical and chemical parameters and hygienic safety requirements for slaughter products intended for the production of meat products for baby food [31]. We consider it necessary to explain that the physical and chemical indicators do not give a complete picture of the product quality, although they show the product ingredients [32]. Definitely, compliance with the hygienic and microbiological requirements of the technical regulations contributes to the prevention of food toxicoinfections and poisoning but does not protect consumers from counterfeiting or intestinal sarcocystosis. Thus, meat products to be sold to the population are not actually examined for safety and quality.

\section{References}

1. L.N. Korobova, Materials of the XII International Scientific and Practical Conference "Safety and quality of goods", 146-159 (2018)

2. L.N. Korobova, Materials of the XII International Scientific and Practical Conference "Safety and quality of goods" Saratov State Agrarian University named after N.I. Vavilov, 134-145 (2018)

3. E.S. Kazaryan, Materials of the International Scientific and Practical Conference "Problems of competitiveness of consumer goods and food products" 149-152 (SouthWestern State University, Kursk, 2019)

4. A.M. Abdullayeva, Colloquium-Journal 13-3 (37), 72-73 (2019)

5. Official website of the Ministry of Agriculture of the Russian Federation. Access mode: https://mcx.gov.ru/ministry/departments/departament-ekonomiki-investitsiy-iregulirovaniya-rynkov/industry-information/info-obzor-rynkov-za-26-02-2021/

6. L.S. Baidalinova, Izvestiya KSTU. Kaliningrad 17, 74-78 (2010)

7. V.V. Chaplinsky, A.A. Dudina, Economics and Business, The look of the young 1, 325-328 (2015)

8. K.A. A.w. Gorshenina, Z.Sh. Amakhanova, Bulletin of Science 1, 6(15), 47-50 (2019)

9. Yu.S. Kichko, M.D. Romanko, M.V. Klychkova, E.V. Gurentyev, Bulletin of Meat Cattle Breeding 4(69), 93-99 (2016)

10. A.D. Dzhamakeeva, A.E. Mikheev, A. Abdraimov, Eurasian Union of Scientists 45(73), 18-23 (2020)

11. I.F. Gorlov, M.I. Slozhenkina, G.V. Fedotova, Yu.D. Grebennikova, R.S. Omarov, Food industry 8, 40-43 (2019)

12. Federal Law No. 2300-1-FZ dated 07.02.1992 (as amended on 08.12.2020) "On consumer rights protection"

13. V.S. Kolodyaznaya, Yu.V. Boyko, Scientific Journal of the SRI ITMO. Series: Processes and devices of food production 3, 51-57 (2015)

14. Federal Law No. 294-FZ dated December 26, 2008 "On protection of rights of legal entities and individual entrepreneurs in the exercise of state sontrol (supervision) and municipal control (as amended on December 8, 2020)

15. GOST 9959-2015. Meat and meat products. General conditions of organoleptical assessment, Moscow, Srandartinform (2016)

16. GOST 19496-2013. Meat and meat products, The method of histological investigation, Moscow, Srandartinform (2019) 
17. GOST 32951-2014. Semi-prepared meat meat-contained product, General specifications, Moscow, Srandartinform (2015)

18. S.A. Timofeevskaya, Abstract journal, Moscow 3, 923 (2017)

19. L.A. Yablonenko, Meat industry 2, 64-65, (2008)

20. N.A. Boldyreva, M.V. Zabolotnykh, Almanac of World Science 3-1(18), 42-43 (2017)

21. E.A. Doronin-Dorgelinsky, T.N. Sivkova, Russian Journal of Parasitology 1, 35-41 (2017)

22. M.P. Butko, P.A. Popov, I.S. Osipova, E.A. Semenova, S.A. Lavina, Problems of veterinary sanitation, hygiene and ecology 2(26), 18-24 (2018)

23. F. Berlingieri, A. Bruno, F. Njeumi, S. Cavirani Rev Sci Tech 26(3), 607-617 (2007)

24. K. Everstine, J. Spink, Sh. Kennedy, J Food Prot 76(4), 723-735 (2015)

25. J. Spink, C. Moyer Douglas, J Food Sci. 76(9), 157-163 (2011)

26. O.V. Arnautov, Vopr Pitan. 85(1), 110-116 (2016)

27. O.V. Arnautov, O.V. Bagryantseva, V.V. Bessonov, Vopr Pitan. 85(2), 104-115 (2016)

28. I.V. Bragina, O.I. Aksenova, B.G. Bokit'ko, A.A. Gorsky, Gig Sanit. 1, 11-13 (2013)

29. G.G. Onishchenko, S.A. Sheveleva, S.A. Khotimchenko, Vopr Pitan. 81(5), 4-12 (2012)

30. M. Shamtsyan, J Sci Food Agric. 94(10), 1966-1969 (2014)

31. Decision of the Council of the Eurasian Economic Commission No. 68 dated 09.10.2013 "On the technical regulations of the Customs Union "On the safety of meat and meat products" (together with "TR TS 034/2013. Technical regulations of the Customs Union. On safety of meat and meat products")

32. S. Bansal, S. Apoorva, M. Manisha et al., Crit Rev Food Sci Nutr. 57(6), 1174-1189 (2017) 